\title{
Screening of mango genetic resource for tolerance against its malformation incidence in Madhya Pradesh, India
}

\author{
Ashish Kumar \\ Department of Plant Pathology, J.N.K.V.V., College of Agriculture, Rewa-486 001 (M.P.), INDIA \\ E-mail: ashishashish2612@gmail.com
}

Received: June 27, 2014; Revised received: August 28, 2014; Accepted: November 07, 2014

\begin{abstract}
The age old enigma of mango malformation control is still unresolved and eluding the scientists to develop a proper control for the malady. Strengthening of the mango genetic resource base for tolerance traits may seem to be viable criteria of research. Though, prior studies have been undertaken in mango malformation incidence, but screening of large set of germ plasm for tolerance traits in multiple years has so far been a lacuna. The current study evaluated the genetic resource comprising of 65 mango varieties for three consecutive years under natural conditions for incidence of floral malformation. The mean malformation incidence varied from $0.47 \%$ to $60.24 \%$. This study revealed that a group of seven varieties namely Bangalora, Baneshan, Dahiyar, Rammanna, Shakul and Safeda showed resistant type of reaction during both the years of evaluation. However, Moovandan showed highly susceptible type of reaction during both the years. Similarly, germplasm were categorized under moderately resistant, moderately susceptible and susceptible category on the basis of their reaction to malformation incidence.
\end{abstract}

Keywords: Floral malformation, Inflorescence type, Mangifera indica

\section{INTRODUCTION}

Mango (Mangifera indica L.), is known as the King of fruits, owing to its diverse uses and increasing significance and great demand in international market (Hafiz et al., 2008). Unfortunately, this crop regularly suffers a colossal loss due to malformation, which is the major impediment in establishment of an economically viable orchard. Malformation is the most widespread and destructive disease of mango and occurs in many mango-growing countries all over the world. This malady manifests in two forms viz. vegetative malformation and floral malformation (Chakraborti and Misra, 2014). In floral malformation reduction in the length of primary axis and the secondary branches of the panicles makes the flowers appear in clusters. The blooms remain as dull green, unopened and persistent buds. Inflorescence and vegetative malformation of mango causes serious losses since malformed inflorescences produce no fruit, or abort at early stages and is directly responsible for reduction in yield (Chakraborti and Misra, 2014). However, its nature is of somewhat arguable as its etiology and control are not well understood in spite of several attempts in direction of determining the nature of this "century-old" disease. Several conflicting reports exist regarding the causal agent of the disease (Kumar et al., 1993). Various entomological, pathological, physiological and biochemical factors have been demonstrated to be the possible causes of this malady (Singh, 2006). Many studies have shown
Fusarium mangiferae pv. subglutinans to be the pathogen responsible for mango malformation disease and Koch's postulates have been completed successfully with this fungus in various countries (Kumar et al., 1993; Ploetz and Gregory, 1993; Freeman et al., 1999). Presence of the eriophyid mite, Aceria mangiferae, has also been claimed to cause mango malformation, but certain studies indicate that mite may only play a role in wounding and transfer of the fungal pathogen to and from infection sites (Kumar et al., 1993; Ploetz et al., 1994). The severity of malformation may vary on the same shoot from light to medium or heavy malformation of panicles. Also, the inflorescence of individual tree may vary due to alternate flowering natute of the crop. Malformation is also spread by grafting, which causes infection of the nursery stock from where the disease is moved to new areas (Kumar et al., 1993; Haggag, 2010). Mango malformation was first reported from India by Watt in 1891, who related the disease to the abnormal growth of plants or plant parts. Lately, the magnitude of losses due to this malady has assumed alarming propositions and the problem is further intensified due to lack of resistance in the mango cultivars against this disease. Further, there is lack of information for ranking of mango varieties for tolerance to floral malformation. A solution oriented approach needs to be developed in order to eliminate such obstacles in mango culture and maintain the economic status of mango through 
sustained and quality production.

In this direction, mango breeders need to focus their research efforts towards developing hybrids of high quality, having more yields and possessing resistant to diseases including malformation. In view of this, the present investigation was undertaken to evaluate the varietal susceptibility against malformation disease of mango. The information generated from this study will be useful to provide base for designing combinations among various varieties and strategies leading to evolution of mango strains tolerant to this malady.

\section{MATERIALS AND METHODS}

The investigation was carried out at Fruit Research Station, Rewa, a district of Madhya Pradesh, during 2010 to 2014. Out of 65 bearing varieties considered for this study, 48 were grouped for observation during 2010-11 and 17 were grouped for 2011-12 based on their alternate fruiting behaviour. The trees/germplasm observed for malformation in 2010-11 was further observed for malformation incidence in 2012-13 and the trees/germplasm observed for malformation in 2011-12 was further observed for malformation incidence in 2013-14 to obtain two years data and to minimize the error due to less/nil fruiting behaviour in consecutive year. Six trees of each germplasm were selected and allowed for natural infection. Screening of varieties is done during the reproductive stage in peak period of flowering i.e. during spring-summer months. The trees were spaced at $10 \mathrm{~m}$ between rows and plants were 5 to $8 \mathrm{~m}$ high depending upon the genotype. There were three general fungicide + insecticide sprays/year (first prior to blooming, second post fruit setting and third after fruit harvesting) for plant protection but no pruning of malformed panicles was practiced in the progeny orchard during, prior year and study period to allow sufficient amount of inoculum under natural conditions. All the panicles of each plant of each taxon were observed carefully and the infected panicles are counted accordingly. A sampler frame of size $(2 \mathrm{~m} \times 1 \mathrm{~m})$ was used on the four sides (North, West, South and East) on the middle height of the canopy of a tree. The total number of healthy and malformed panicles in the frame were counted and averaged. For each of the germplasm, four replicates were maintained. Plant reaction against floral malformation was measured using 0 to 5 scales (Table 1 ). The yearly mean data along with pooled data of two year study are presented in this treatise. The germplasm was grouped based on their reaction of resistance and susceptibility using DARwin ver. 5.0.158 (Perrier and Jacquemound-Collet, 2006) and a dendrogram was generated using ordinal joining to represent the germplasm under different categories.

\section{RESULTS AND DISCUSSION}

All the genotypes clearly differed in intensities of malformation and have been ranked accordingly. Based on two years data, it was noticed that mean malformation incidence ranged from $0.47 \%$ to $60.24 \%$ (Table 2). The highest mean malformation incidence of $60.24 \%$ was recorded in Moovandan, which produced loose and open type of inflorescence. The cultivar Moovandan thus proved to be the most susceptible cultivar for mango malformation among all evaluated varieties. This was followed by Hapus and Sunderja where $51.63 \%$ and $36.86 \%$ mean malformation was recorded, respectively. However, both the varieties, Hapus and Sunderja differed markedly in their inflorescence type and produced highly compact and loose and open type respectively. There is no totally resistant or immune variety expressing no visible sign with PDI range 0.00 and rating scale 0 . A set of ten varieties namely Bangalora, Dahiyar, Baneshan, Rammanna, Safeda, S.B. Chausa, Shakul, Khazura, Neeleshwari and Chandrakaran showed less than $6 \%$ of mean malformation incidence and hence can be categorized under resistant category. A set of 18 varieties showed 6.00 to $10.00 \%$ mean malformation incidence and hence can be categorized under moderately resistant type. Further, 27 varieties showed mean malformation incidence between 11-20\% and were categorized under moderately susceptible. A set of 8 varieties showed $21-40 \%$ of mean malformation incidence and were categorized under susceptible category and two varieties namely Moovandan and Hapus showed more than $41 \%$ of mean malformation incidence and were categorized under highly susceptible type. The inflorescence type varied from loose and open type to highly compact type and depicted no co-relation with malformation incidence. The inflorescence type of malformed panicles resembles the original morphology of respective variety.

To observe a clear pictorial view of susceptible and resistance germplasm, grouping was performed (Fig. 1) and it was observed that Bangalora, Baneshan, Dahiyar, Rammanna, Shakul and Safeda clearly showed resistance type of reaction (less than 5\% mean malformation incidence) on both the years of evaluation and can be categorized

Table 1. Rating of floral mango malformation susceptibility.

\begin{tabular}{llcc}
\hline Score & Range of panicle infected (\%) & Symptoms expressed & Reactions \\
\hline 0 & 0 & No visible symptom & Total resistant/immune \\
1 & $0.10-5.00$ & Very low & Resistant \\
2 & $6.00-10.00$ & low & Moderately resistant \\
3 & $11.00-20.00$ & Intermediate & Moderately susceptible \\
4 & $21.00-40.00$ & High & Susceptible \\
5 & $41.00-100.00$ & Very high & Highly susceptible \\
\hline
\end{tabular}




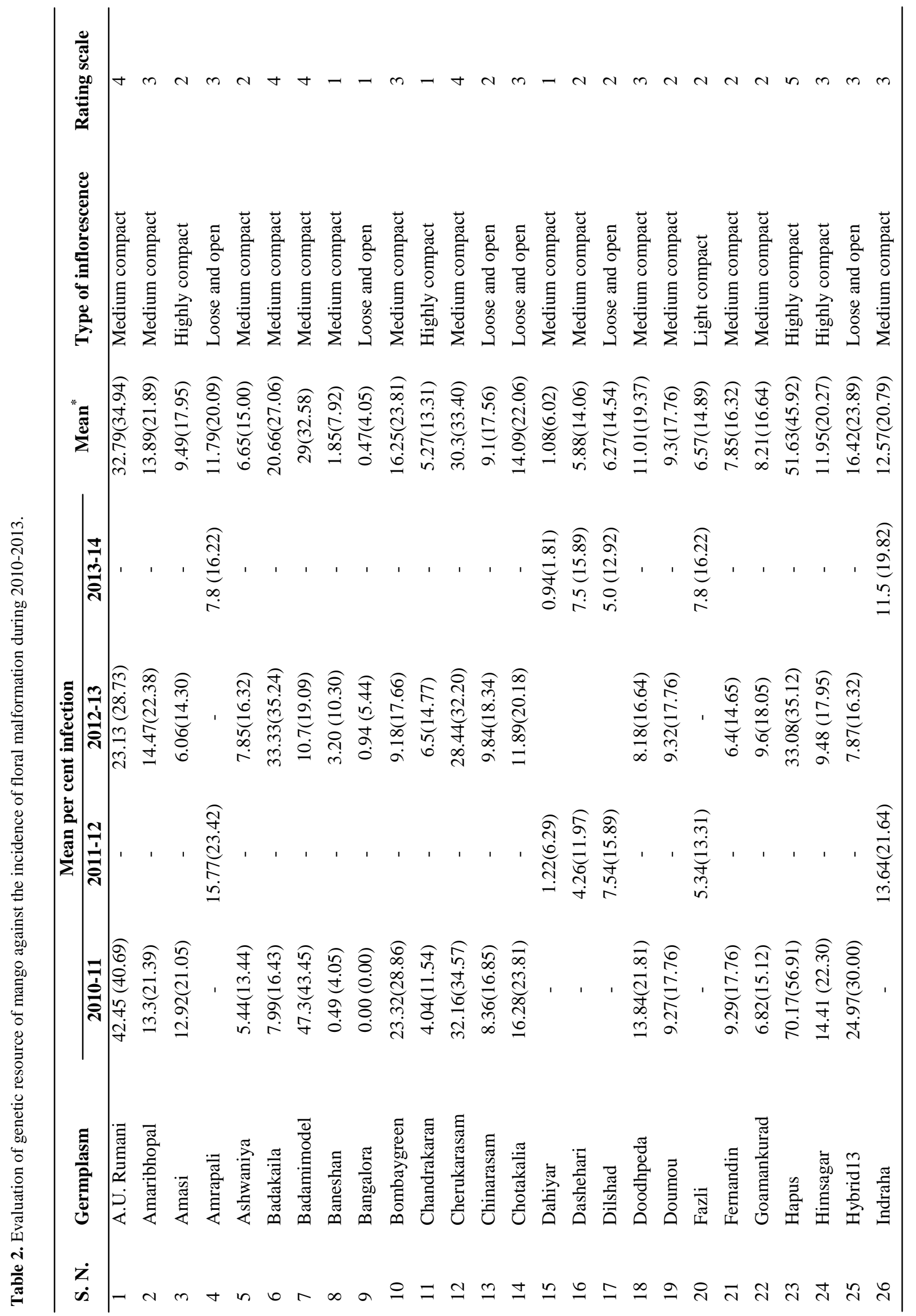




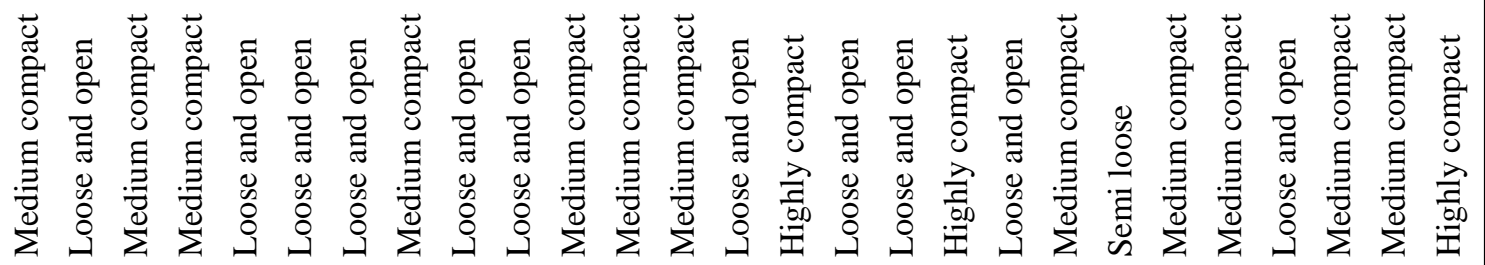

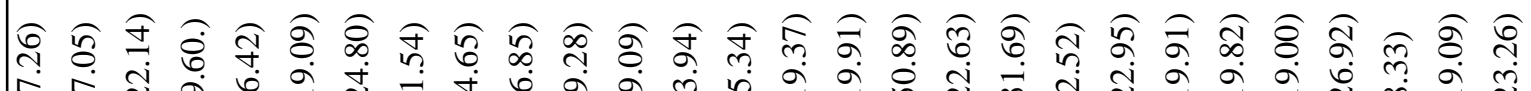

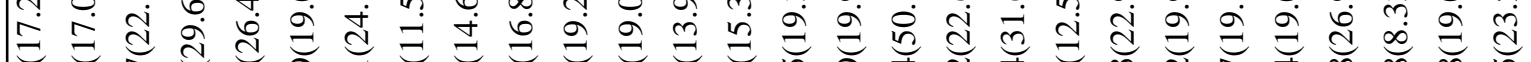
ॠ

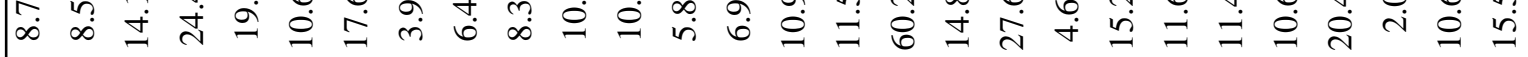

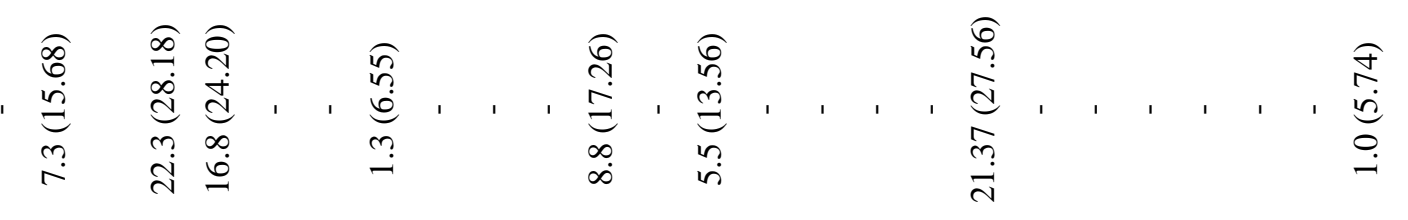

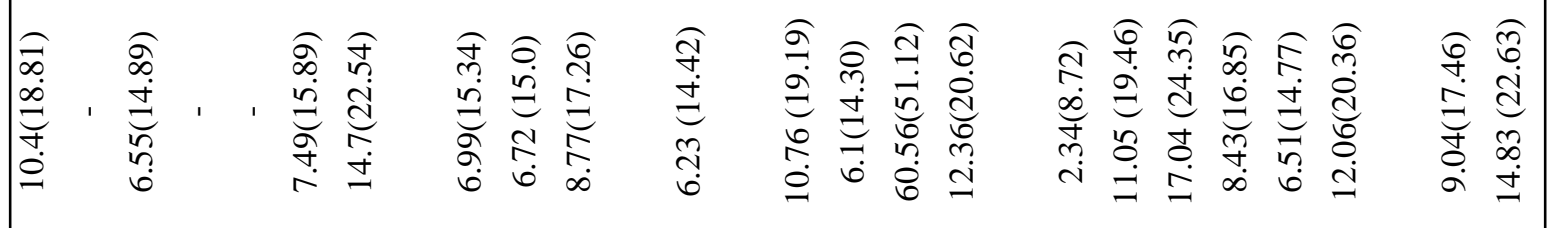

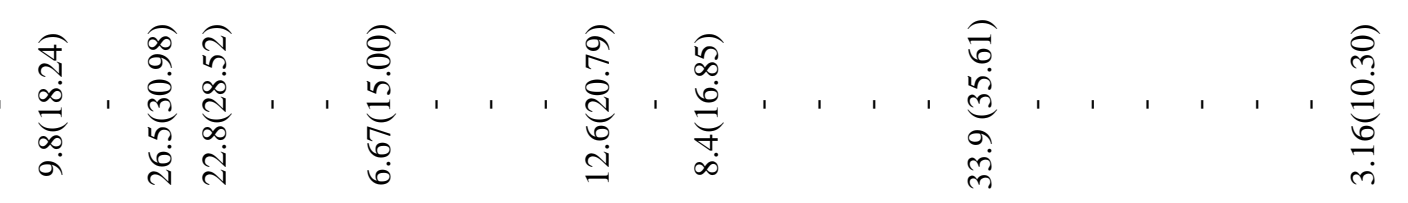

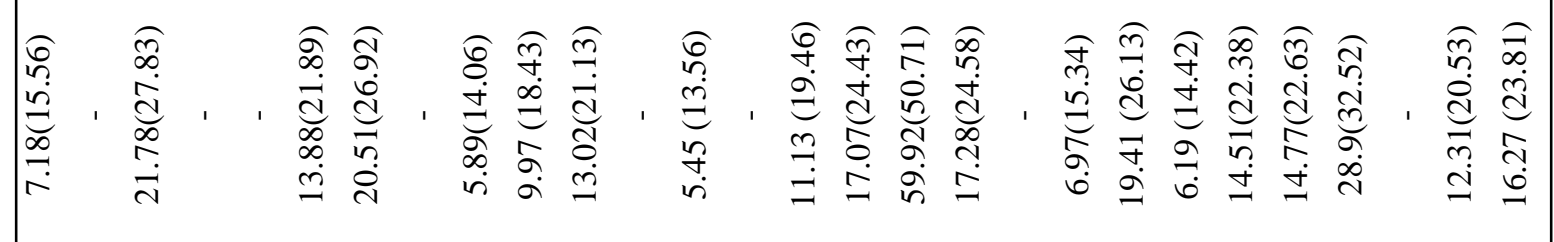

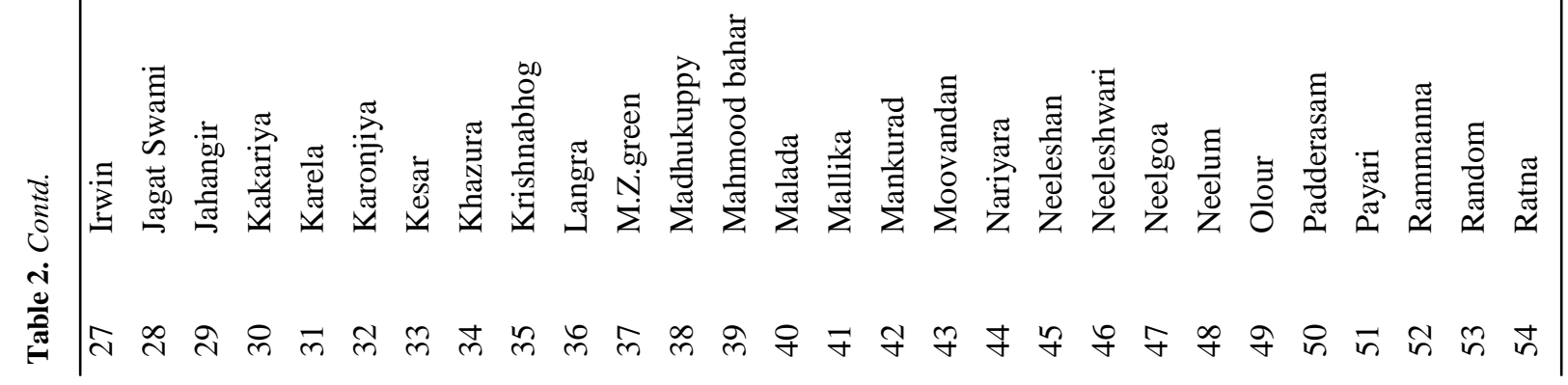


under resistant category. However, Khazura, Chandrakaran, S.B. Chausa and Neeleshwari showed deviation in their malformation incidence during the evaluation years and hence can't be said as actually resistant category. They can only be categorized as either resistant or moderately resistant depending upon other factors affecting the incidence of malformation. Similarly, Amasi and Sensation showed the deviation from the classes of moderately resistant and moderately susceptible based on two years data and hence can't be assumed under moderately resistant category. Hence, on the same basis, Doumou, Chinarasam, Fernandin, Malada, Goamankurad, Langra, Krishanbhog, Irwin and Jagatswami can be categorized as moderately resistant. Under the category of moderately susceptible, Chotakalia, Amaribhopal, Ratna, Indraha, Velaikolamban, Mallika, Nariyara and Neelgoa were confirmed. Moovandan was categorized as highly susceptible germplasm. However, Hapus, A.U. Rumani and Sunderja can be scored under the category of susceptible or highly susceptible. One germplasm, namely Badamimodel showed high variation in their reaction to malformation incidence during two years of observation and hence needs to be inspected for longer period to draw a conclusive remark.

The interaction of the host genotype to the pathogen may be responsible for this variation in the disease intensity among varieties. The incidence of malformation is further influenced by several factors like tree growth habit (time of flushing), physiology, rate of transpiration and cellular structure. Circumstantial evidences have been provided by several workers on physiological aspects of the mango crop cultivars in relation to incidence of malformation. Reports have indicated that early-emerging flower buds were severely infected; whereas later buds escaped the disease; the relatively high temperature during panicle development was said to be the cause of the difference (Kumar et al., 1993). In India, the disease is present in all mango-producing areas; however, the incidence is lower in the southern and eastern than in the northern region. Similarly, in the present finding the varieties from South like Bangalora and Baneshan have less malformation incidence. Singh et al. (1998) also stated that elevating the temperature of the orchard during flower genesis can minimize the occurrence of floral malformation. Susceptible cultivars were found to have higher rate of transpiration with a concomitant increase in relative humidity and increased moisture holding capacity by malformed tissues. Higher rate of transpiration which was recorded in susceptible cultivar was attributed to presence of higher number of stomata as has been reported in other crops (Singh, 2006). Lower leaf temperature and higher relative humidity in susceptible cultivars were also demonstrated by Varma et al. (1971), where it was observed that the fungus Fusarium mangiferae (pv. moniliforme var. subglutinans), the casual organism of mango malformation, grows well at lower temperature 


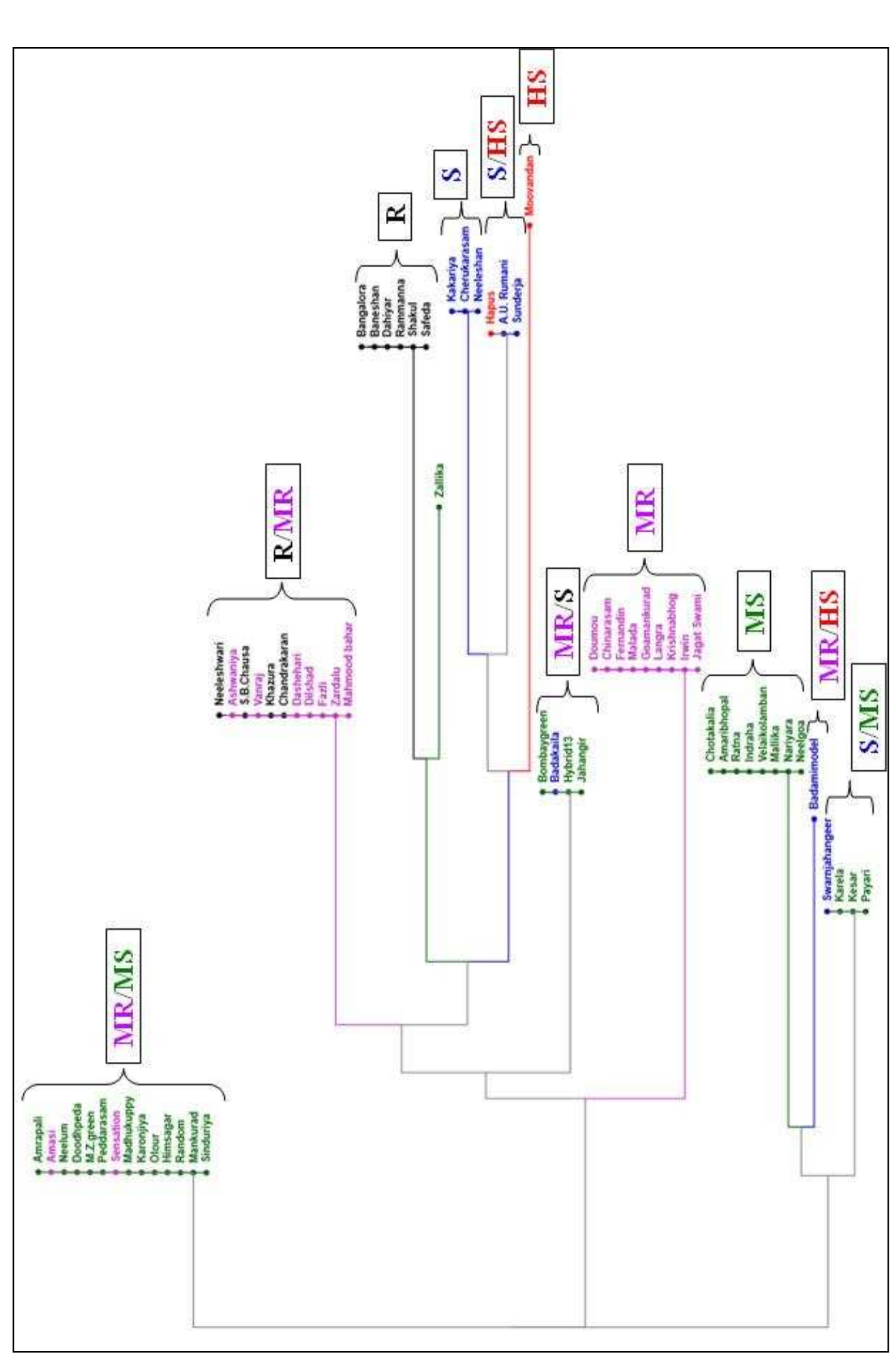

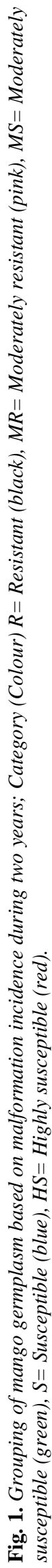


and higher relative humidity. The varieties investigated in present work provide a variable genetic makeup differing in physiological aspects and it will be highly valuable to investigate the germ plasm available according to aforesaid factors. The availability of more sugar contents in Hapus (more sweet variety) may favour proliferation of pathogen and thus make it more susceptible for the attack. Similarly, Ram et al. (1990) has also reported that varieties with higher sugar content like Bombay Green and Hapus showed a high percentage of malformed panicles (10.8-24.2\%). Depending upon the cellular structure and physiology under environmental factors, the shape and structure of the panicles differed markedly among the varieties (Chakrabarti et al., 1990). Similarly malformed inflorescences of different varieties were variable in context of their shapes, sizes, growth and level of compactness. In case of Langra variety, malformed inflorescences continue their growth and attain a specific shape that can be recognized even from a distant place.

\section{Conclusion}

On the basis of the current study, it can be clearly understood that mango germ plasm has differential reaction to malformation incidence. This information is of immense value for further studies and evaluations and for designing strategies to combat the disease. The varieties categorized as resistant or moderately resistant like Bangalora, Baneshan, Dahiyar, Rammanna, Shakul and Safeda may be used as rootstock for the susceptible varieties so as to elude malformation incidence. Further studies need to be carried out to evaluate the most promising rootstocks for malformation resistance. The data obtained in the current study can be used for strengthening of mango germ plasm by using molecular biology tools. Thus, this study of screening mango germ plasm for tolerance against malformation incidence opens a gateway which was so far missing. Novel investigation in direction of fortifying mango germ plasm against malformation can be carried out on basis of this study.

\section{ACKNOWLEDGEMENTS}

Author owes his gratitude to Dr. J. Singh, Dr. T.K. Singh and Dr. S.K. Tripathi for providing annual report of AICRP on Mango for the year 2010-11.

\section{REFERENCES}

Chakrabarti, D.K., Singh, A. and Singh, K. (1990). Physiological and biochemical changes induced in accumulated mangiferin in Mangifera indica L. Journal of Horticultural Sciences, 65: 731-737.

Chakraborti, K. and Misra, D.K. (2014). Evaluation of taxa for tolerance agaimst floral malformation in Gangetic West Bengal. Universal Journal of Plant Sciences, 2(2): 27-30.

Freeman, S., Maimon, M. and Pinkas, Y. (1999). Use of GUS transformants of Fusarium subglutinans for determining etiology of mango malformation disease. Phytopathology, 89: 456-61.

Hafiz, I.A., Ahmad, S., Abbasi, N.A., Anwar, R., Chatha, Z.A. and Grewal, A.G. (2008). Intensity of panicle malformation in mango (Mangifera indica L.) varieties. Pakistan Journal of Agricultural Sciences, 45(4): 418423.

Haggag, W.M. (2010). Mango diseases in Egypt. Agriculture and Biology Journal of North America, 1(3): 285-289.

Kumar, J., Singh, U.S. and Beniwal, S.P.S. (1993). Mango malformation: One hundred years of research. Annual review of Phytopathology, 31: 217-232.

Perrier, X. and Jacquemound-Collet, J.P. (2006). DARwin software. Retrieved from www.darwin.cirad.fr/darwin

Ploetz, R.C. and Gregory, N.F. (1993). Mango malformation in Florida: distribution of Fusarium subglutinans in affected trees, and relationships among strains within and among different orchards. Acta Horticulturae, 341:388-94.

Ploetz, R.C., Zentmyer, G.A., Nishijima, W.T., Rohrbach, K.G. and Ohr, H.D. (1994). Compendium of Tropical Fruit Diseases. APS Press, St Paul, MN, USA.

Ram, R.B., Singh, B.P. and Singh, S.P. (1990). Studies on malformation of mango (Mangifera indica L.) inflorescence with reference to varieties and age of the tree. Horticultural Journal, 3: 31-36.

Singh, V.K. (2006). Physiological and biochemical changes with special reference to mangiferin and oxidative enzymes levels in malformation resistant and susceptible cultivars of mango (Mangifera indica L.). Scientia Horticulturae, 108: 43-48.

Singh, V.K., Saini, J.P. and Misra, A.K. (1998). Mango malformation in relation to physiological parameters under elevated temperature. Indian Journal of Plant Physiology, 3: 231-233.

Varma, A., Raychaudhary, S.P., Lele, V.C. and Ram, A. (1971). Preliminary investigations on epidemiology and control of mango malformation. Proceedings of Indian National Science Academy, 57: 291-300. 